\title{
VARIATION IN DIRECTION OF PROPAGATION OF LONG ELECTROMAGNETIC WAVES
}

\author{
By Lieut. Commander A. Hoyt Taylor, U. S. N. R. F.
}

\section{CONTENTS}

I. Introduction

I

II. Method of getting absolute minimum with direction finders.......... 420

III. Comparison of maximum and minimum methods. . . . . . . . . . . 42 I

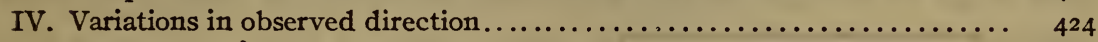

V. Possible causes of the variation of apparent bearing. ............. 426

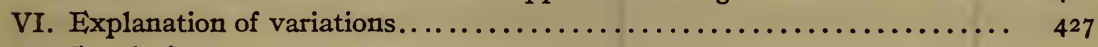

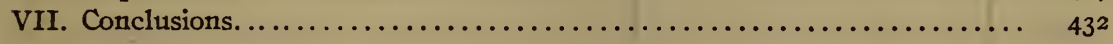

\section{INTRODUCTION}

The investigation herein reported was an outcome of a study of the properties of an extremely long-wave direction-finder coil, with a view to determining the feasibility of using such long-wave direction finders on large aircraft on long flights, such as, for instance, a trans-Atlantic flight. The use of direction finders for aircraft having been carried to such a very satisfactory conclusion at the Naval Air Station, Hampton Roads, Va., on a wave length of $2500 \mathrm{~m}$, it seemed highly desirable to ascertain if it might be possible to utilize for airplane direction-finder work existing highpower stations in Europe in case of extremely long flights. Since all of the trans-Atlantic stations which may be considered to be really high-power stations operate on continuous waves of lengths between 8000 and $20000 \mathrm{~m}$, it was decided to build a directionfinder coil at the Naval Aircraft Radio Laboratory, Bureau of Standards, of suitable dimensions for installation in a type $\mathrm{F}-5-\mathrm{L}$, type $\mathrm{H}-\mathrm{I} 6$, or type $\mathrm{NC}$ flying boat.

In the process of this study, comparison was made of the relative accuracy of settings obtainable with the two-coil maximum method and the usual single-coil minimum method. It was noticed that there were very considerable variations in the apparent bearing of the Naval Radio Station at New Brunswick, N. J., 
transmitting on $13600 \mathrm{~m}$, and a series of observations were undertaken with a view to determining whether these apparent variations of bearing were of local origin or not.

\section{METHOD OF GETTING ABSOLUTE MINIMUM WITH DIRECTION FINDERS}

When a direction-finder coil is placed with its plane at right angles to the direction of propagation of electromagnetic waves, the resulting signal is not exactly zero, owing to the antenna effect in the coil and to other effects of less importance. This is because the antenna effect is approximately $90^{\circ}$ out of phase with the true direction-finder effect. Settings of the coil are, therefore, not as sharp as they would be if an absolute minimum existed. In con-

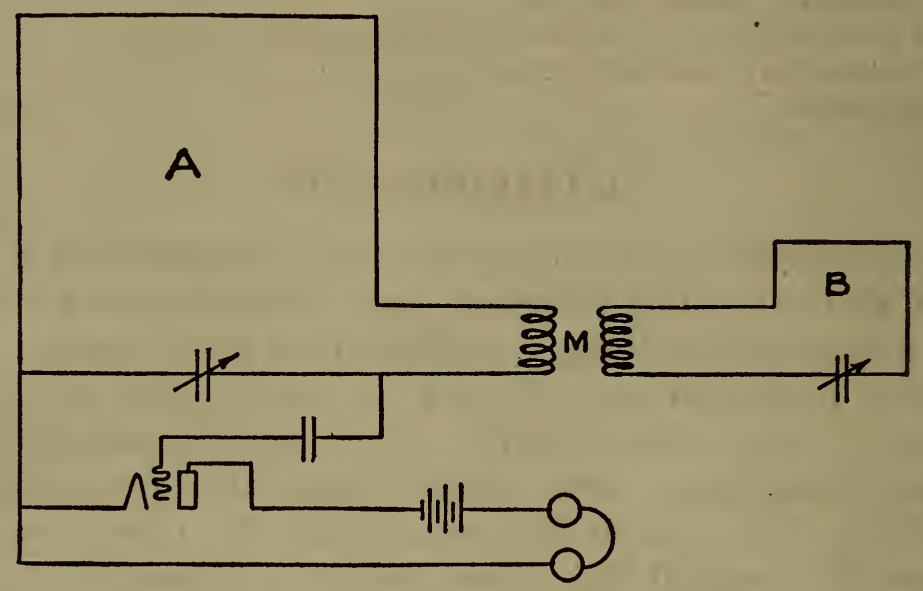

FIG. I

nection with the long-wave direction-finder work undertaken at this laboratory, it has been found possible to produce an absolute minimum by introducing a small component of signal differing $180^{\circ}$ in phase from the undesirable effect, by the method indicated below, to which Fig. I refers.

The apparatus consists of a long-wave direction finder, dimensions 35 by 30 inches, with three layers of litzendraht wire, each layer containing 40 turns, spaced three-sixteenths inch, represented by $A$ in Fig. I. A standard receiving circuit, without coupling, was used with two stages of amplification (not shown in Fig. I). A small auxiliary coil $B$ was very loosely coupled at $M$. with the main coil and tuned to very nearly the same wave length. The method of operation is as follows: The auxiliary coil $B$ is detuned, the coupling $M$ made approximately zero, and the coil $A$ rotated 
to a minimum. It is found that upon New Brunswick and Annapolis on 13600 and $16700 \mathrm{~m}$, respectively, the strength of signal varies between 600 and 2000 , according to the degree of amplification used, and the best minimum which is obtainable without compensation is, roughly, I per cent of the maximum. When the best minimum has been obtained with coil $A$, coil $B$ is placed at approximately right angles to $A$, so that it has no coupling with $A$. Coil $B$ is then tuned to the same wave and the coupling at $M$ is adjusted. Exact opposition in phase is obtained by a very slight detuning of the coil $B$. The operation is very simple and quickly made, a suitable adjustment of the coupling $M$ making it possible to obtain an absolute minimum with coil $A$.

This method of obtaining an absolute minimum was reported to the direction-finder experts of the Philadelphia Navy Yard with the suggestion that they try it out on short-wave spark stations. Expert Radio Aid Stuart Ballentine made this matter the subject of a lengthy report, in which he concluded that while the method was accurate and capable of application at all wave lengths, it was not practicable on $600-\mathrm{m}$ waves on account of the precision of adjustment required. The writer concurs fully with the Ballentine report. There are other methods more suitable for short-wave work.

\section{COMPARISON OF MAXIMUM AND MINIMUM METHODS}

A telescope and scale were arranged in connection with a mirror on coil $A$, the distance between the mirror and scale being such that $3.5 \mathrm{~cm}$ on the scale equaled $\mathrm{I}^{\circ}$. The accuracy with which settings may be duplicated is shown by the following table. Readings were taken on Annapolis on a very clear day. The readings extended over a period of about one and one-half hours. It was found best to choose the pitch of the signal rather high.

\begin{tabular}{|c|c|c|}
\hline $\begin{array}{c}\text { Readings in } \\
\text { centimeters }\end{array}$ & $\begin{array}{c}\text { Deviation from } \\
\text { average in } \\
\text { centimeters }\end{array}$ & $\begin{array}{c}\text { Deviation from } \\
\text { average in } \\
\text { degrees }\end{array}$ \\
\hline 71.0 & -0.1 & -0.03 \\
71.5 & +.4 & +.12 \\
71.2 & +.1 & +.03 \\
70.9 & -.2 & -.06 \\
71.0 & -.1 & -.03 \\
71.0 & -.1 & -.03 \\
71.2 & +.1 & +.03 \\
Av. & & \\
\hline
\end{tabular}


The following table is taken on the compensation wave of Annapolis:

\begin{tabular}{|c|c|c|}
\hline $\begin{array}{c}\text { Readings in } \\
\text { centimeters }\end{array}$ & $\begin{array}{c}\text { Deviation from } \\
\text { average in } \\
\text { centimeters }\end{array}$ & $\begin{array}{c}\text { Deviation from } \\
\text { average in } \\
\text { degrees }\end{array}$ \\
\hline 70.5 & +0.1 & +0.29 \\
69.5 & .0 & .0 \\
69.1 & -.04 & -.12 \\
68.6 & -.09 & -.26 \\
70.3 & +.08 & +.23 \\
69.4 & -.01 & -.03 \\
69.0 & -.05 & -.14 \\
69.7 & +.02 & +.06 \\
69.5 & .0 & .0 \\
69.5 & .0 & .0 \\
\hline
\end{tabular}

It will be noted that the general average on the compensation wave differs by $\mathrm{r} .6 \mathrm{~cm}$, or $0.46^{\circ}$, from the general average on the main wave. This difference might have been due to a greater accuracy, which is evident on the settings of a higher-pitched note, the compensation wave being of lower pitch. On the other hand, it was suspected that the set was not quite as accurately compensated for minimum on the last series. The set was therefore thrown completely out of adjustment and the minimum balanced out, with special attention to the compensation wave of Annapolis and the following readings, in centimeters, obtained: 7 I.o, 7 1.0, 7 1.0, 71.0, and 70.9. The error here is too small to be calculable and the readings agree with those obtained upon the main wave.

In order to test the relative accuracy of the maximum method as used in airplanes with the ordinary minimum method, the following two series of readings were obtained on New Brunswick's I $3600 \mathrm{~m}$ wave.

- MAXIMUM METḤOD

\begin{tabular}{|c|c|c|}
\hline $\begin{array}{c}\text { Readings in } \\
\text { centimeters }\end{array}$ & $\begin{array}{c}\text { Deviation from } \\
\text { average in } \\
\text { centimeters }\end{array}$ & $\begin{array}{c}\text { Deviation from } \\
\text { average in } \\
\text { degrees }\end{array}$ \\
\hline 20.5 & +1.2 & +0.34 \\
17.0 & -2.3 & -.66 \\
20.0 & +.07 & +.20 \\
19.8 & +.05 & +.14 \\
Av. 19.3 & & \\
\hline
\end{tabular}


MINIMUM METHOD

\begin{tabular}{|r|r|r|}
\hline 18.0 & -0.15 & -0.43 \\
20.6 & +.11 & +.31 \\
21.0 & +.15 & +.43 \\
17.3 & -.22 & -.63 \\
$\frac{20.5}{-}$ & +.10 & +.29 \\
\hline Av. 19.5 & & \\
\hline
\end{tabular}

It is evident that the accuracy of the setting that may be obtained with the maximum method is not much inferior to that obtained with the ordinary minimum method. It is known, however, that the maximum method requires a far higher degree of experience on the part of the operator, as is shown by the following table taken with the maximum method by another. observer of less experience:

MAXIMUM METHOD

\begin{tabular}{|c|c|c|}
\hline $\begin{array}{c}\text { Readings in } \\
\text { centimeters }\end{array}$ & $\begin{array}{c}\text { Deviation from } \\
\text { average in } \\
\text { centimeters }\end{array}$ & $\begin{array}{c}\text { Deviation from } \\
\text { average in } \\
\text { degrees }\end{array}$ \\
\hline 22.0 & +0.50 & +0.14 \\
25.0 & +4.5 & +1.29 \\
20.0 & -1.5 & -.43 \\
19.0 & -2.5 & -.71 \\
Av. 21.5 & & \\
\hline
\end{tabular}

MINIMUM METHOD

\begin{tabular}{|r|r|r|}
\hline 21.5 & -0.4 & -0.11 \\
22.5 & +.6 & +.17 \\
23.0 & +1.1 & +.31 \\
$\frac{20.5}{\text { Av. } 21.9}$ & -1.4 & -.40 \\
\hline
\end{tabular}

Undoubtedly when the compass is swung the use of the method of compensation of minimum herein outlined will give slightly different distortion curves than those obtained without compensation, but this should not involve any new difficulty as long as the distortion curve is known. It makes no difference what its shape is, provided none of the distortions are large.

The relative precision of the minimum method as compared with the maximum method depends largely on the character of disturbing interference and strays. In general, when the strays are very heavy and coming with nearly equal intensity from all points of the compass, the maximum method gives better results 
than the minimum, because the minimum is badly obscured by the strays. But in the case of interfering signals this may not be true, as the interfering signal may come from such a direction that the reversal of the cross coil used in the maximum method may cause enormous difference in the intensity of the interference signal, thereby obscuring the setting obtainable with the maximum method in a manner even more detrimental to the results than the obscuration which would be obtained with the minimum method.

The maximum method was originated in England, and is called the Robinson method. It consists of the use of two directionfinder coils wound at right angles to each other and fixed on a common support so that they can be rotated together. One coil, known as the $A$ coil, lies roughly in the plane of propagation of the observed signal, and the other coil, known as the $B$ coil, is therefore roughly at right angles to it. If the $B$ coil is exactly at right angles to the signal, reversal of the $B$ coil will not change the strength "of the received signal, which remains equal to the maximum signal obtainable with the $A$ coil alone. The method of operation is to keep reversing the $B$ coil until the signal seems to have the same intensity in either position of the reversing switch. The advantage of the maximum method lies in the fact that a loud signal can be heard at all times, and therefore the device can be used in an airplane where the minimum method would be impossible on account of engine noise. A device is usually provided whereby the $A$ coil can be used alone in order to determine the general direction of the signal, said device consisting merely of suitable inductance or capacity to bring the tuning of the circuit to the same point where the $A$ coil is cut in or cut out.

\section{VARIATIONS IN OBSERVED DIRECTION}

Observations of the same character as those included in the preceding paragraph were then made from day to day for long periods of time during the day, and it was noticed that on signals from Annapolis, on $16700 \mathrm{~m}$, distant only 35 miles, the settings could be repeated from day to day and from hour to hour with fair accuracy, but that readings taken near the sunset hour and at night showed variations of a number of degrees. When observations were made on New Brunswick's wave of $13600 \mathrm{~m}$ (distance from Washington to New Brunswick about I 75 miles), very large deviations were frequently observed, as the following table, which constituted only a small share of the observations 
actually taken, will show. A direct reading scale in degrees was attached to the rotating coil, as the deviations were so large that it was not necessary to use the mirror and scale to determine them. The degrees in the table are not true bearing, but rather of a purely arbitrary scale. Two days upon which the observations were taken were very foggy, being January 22 and 23 , I9I9.

\begin{tabular}{|c|c|c|c|c|c|}
\hline \multicolumn{2}{|l|}{ ANNAPOLIS } & \multicolumn{2}{|l|}{ ANNAPOLIS } & \multicolumn{2}{|c|}{ NEW BRUNSWICK } \\
\hline Time & $\begin{array}{l}\text { Degrees } \\
\text { direction- } \\
\text { finder } \\
\text { setting }\end{array}$ & Time & $\begin{array}{l}\text { Degrees } \\
\text { direction- } \\
\text { finder } \\
\text { setting }\end{array}$ & Time & $\begin{array}{l}\text { Degrees } \\
\text { direction- } \\
\text { finder } \\
\text { setting }\end{array}$ \\
\hline Jan. 22: & & 7.35 p. m..... & 24.0 & Jan. 22: & \\
\hline $12.00 \mathrm{~m} . .$. & 20.5 & 7.36 p. m... & 23.0 & 11.27 a. m.. & 75.8 \\
\hline 1.48 p. m... & 23.9 & 7.40 p. m..... & a 23.0 & 11.28 a. m. . & 75.8 \\
\hline 1.49 p. m.... & 21.7 & 7.42 p. m.. & 24.0 & 11.30 a. m.. & 75.9 \\
\hline 1.50 p. m... & 21.5 & 7.43 p. m.. & 26.0 & 11.40 a. m. . & 75.9 \\
\hline 1.55 p. m.... & 20.0 & 7.45 p. m........ & 27.0 & 12.01 p. m.. & 79.5 \\
\hline $1.56 \mathrm{p} . \mathrm{m} . .$. & 21.0 & 7.46 g. m............ & * 26.5 & 12.05 p. m. . & 80.0 \\
\hline 1.57 p. m..... & 19.5 & 9.07 p. m... & 25.5 & 12.10 p. m. . & 75.8 \\
\hline 1.58 p. m..... & 19.0 & 9.10 p. m... & 25.5 & 3.10 p. m.. & 70.9 \\
\hline 2.00 p. m......... & 18.8 & 9.12 p. m... & 23.5 & 3.12 p. m... & 70.2 \\
\hline 2.02 p. m...... & 19.5 & 9.13 p. m......... & 23.5 & 3.45 p. m......... & 75.0 \\
\hline 2.26 p. m..... & 20.5 & 9.15 p. m........ & 23.5 & 4.47 p. m........ & 62.0 \\
\hline 2.30 p. m... & 20.0 & 9.25 p. m.. & $a 23.0$ & 5.19 p. m.... & 66.9 \\
\hline 2.46 p. m......... & 20.8 & 9.50 p. m........ & a 26.0 & 7.05 p. m.... & $(b)$ \\
\hline $3.02 \mathrm{p} . \mathrm{m} . . . . .$. & 23.0 & 9.54 p. m........ & 25.5 & 7.51 p. m......... & 66.5 \\
\hline •3.04 p. m......... & 21.5 & 9.55 p. m.......... & 25.5 & 7.55 p. m......... & 67.0 \\
\hline 3.05 p. m.... & 21.0 & Jan. 23: & & $7.57 \mathrm{p} . \mathrm{m} .$. & $a_{64.0}$ \\
\hline 3.47 p. m... & 20.0 & $2.07 \mathrm{p} . \mathrm{m}$ & 21.5 & 8.52 p. m...... & 68.0 \\
\hline 3.52 p. m......... & 20.0 & 2.44 p. m......... & - 19.7 & 8.55 p.m........ & 69.0 \\
\hline 4.46 p. m........ & 24.6 & 2.52 p. m....... & 20.5 & 8.57 p. m......... & 72.0 \\
\hline 5.04 p.m... & 22.0 & 3.01 p. m.. & 20.2 & 8.58 p. m... & 73.0 \\
\hline 5.06 p. m......... & 21.5 & 3.07 p. m........ & 20.0 & 8.59 p. m.... & 72.0 \\
\hline 5.07 p.m......... & 20.5 & $3.08 \mathrm{p} . \mathrm{m} . . . .$. & 19.5 & 9.00 p. m.... & 71.0 \\
\hline $5.17 \mathrm{p} . \mathrm{m} . . . . .$. & 20.0 & $3.08 \frac{1}{2}$ p. m....... & 20.5 & 9.01 p. m.. & 71.2 \\
\hline $7.22 \mathrm{p} . \mathrm{m} . . . . .$. & 26.0 & 3.09 p. m........ & 19.8 & 9.03 p. m... & 71.5 \\
\hline 7.25 p. m......... & 26.0 & $3.10 \mathrm{p} . \mathrm{m} . . . . .$. & 19.7 & Jan. 23: & $\cdot$ \\
\hline $7.26 \mathrm{p} . \mathrm{m} . . . . .$. & 26.2 & & & 3.41 p. m............ & 74.0 \\
\hline 7.27 p. m.......... & 26.5 & & & 4.14 p. m. . . . . . . & 75.0 \\
\hline 7.30 g. m.......... & a. 26.5 & & & $4.26 \mathrm{p} . \mathrm{m} . . . . .$. & 72.5 \\
\hline $7.32 \mathrm{p} . \mathrm{m} . . . . .$. & 27.0 & & & 5.02 p. m......... & 73.5 \\
\hline 7.34 p. m......... & 25.0 & & & 5.03 p. m........ & 74.0 \\
\hline
\end{tabular}

$a$ Minimum very broad, unable to compensate.

b Minimum too broad for observation.

It will be seen that the maximum observed variation of the apparent direction of Annapolis is $8.2^{\circ}$ and in the case of New Brunswick $18^{\circ}$. The maximum observed rate of change of apparent bearing in the case of Annapolis was $2.2^{\circ}$ per minute and occurred at $\mathrm{r} .48 \mathrm{p}$. m. on January 22. A number of cases occur where the variation on Annapolis is in the neighborhood of $2^{\circ}$ per minute. In the case of New Brunswick the maximum observed 
rate of change of bearing was $1.5^{\circ}$ per minute, which was noted at 7.55 p. m. and 8.57 p. m. on January 22 . Observations have, however, been made on New Brunswick showing much larger rates of change than those appearing in this table. Many of these early observations were discredited, as the results seemed to be so totally at variance with results obtained by the Navy Department on short-wave work that the whole matter was thought to be due to some peculiarity of the installation at this laboratory.

\section{POSSIBLE CAUSES OF THE VARIATION OF APPARENT BEARING}

It having been suggested that the variation was due to some peculiarty of the method of compensated minimum outlined in this paper, a large number of observations were taken with the ordinary minimum method, and variations of exactly the same order of magnitude were discovered, although the accuracy of the settings was naturally not so great. The method of compensated minimum is not, therefore, responsible for any of these variations, but merely enables them to be detected more readily. A creeping variation may often be detected in the course of a few seconds, since the accuracy of settings with the new method is of the order of one-tenth of $\mathrm{I}^{\circ}$.

The possibility of reradiation from local circuits and other antennas at the Bureau of Standards causing a shift in the apparent bearing was than considered. A number of observations were taken on four different evenings between ro and I 2 o'clock, between the roth and 2oth of December. An investigation showed that no antennae were being used at that time and that all electrical circuits were practically constant in this neighborhood. Evien greater variations than those reported in this series were observed. Finally the antenna at the Naval Radio Aircraft Laboratory which terminates within 20 feet of the direction-finder coil was tuned to the wave length under observation. The following table shows the data obtained on Annapolis taken on January 23:

\begin{tabular}{|c|c|c|}
\hline & Time & Setting \\
\hline Without aerial tuned in.. & 2.44 p. m... & 19.7 \\
\hline With aerial .............. & 2.51 p. m.. & 19.5 \\
\hline Without aerial tuned in.. & $2.52 \mathrm{p.m} .$. & 20.5 \\
\hline With aerial......................................... & $2.53 \mathrm{p} . \mathrm{m} .$. & 21.0 \\
\hline With aerial lead brought within 8 inches of coil. & 3.00 p. m... & 24.0 \\
\hline Without aerial tuned in $\ldots \ldots \ldots \ldots \ldots$ & $3.01 \mathrm{p} . \mathrm{m} \ldots$ & 20.2 \\
\hline
\end{tabular}


This table shows conclusively that the tuning in of the aerial produces no effect unless a lead from the aerial is brought within a few inches of the coil, and even with this greatly exaggerated case of reradiation it was only possible to rotate the apparent bearing through $3.8^{\circ}$. The change between $2.44 \mathrm{p}$. m. and 2.53 p. m. from 19.7 to 21 .o is merely what might be called the normal drift of the apparent bearing and can not be ascribed to the tuning in of the aerial.

\section{EXPLANATION OF VARIATIONS}

These severe tests of the effect of reradiation from antennas and other accidentally tuned circuits show that the changes dealt with in this paper are of an order of magnitude which can not be ascribed to local conditions at the Bureau of Standards. The writer has information that variations of this sort as high as $20^{\circ}$ have been noted by British observers. The variations must therefore be ascribed to reflection and refraction effects and it is believed that they are fully in accord with the most modern notions of the manner of propagation of electromagnetic waves over the surface of the earth. These observations are therefore merely a confirmation of an already fairly well-known phenomena of reflection and refraction of electromagnetic waves from or through banks of more or less ionized layers of the atmosphere, clouds, fogs, etc. The result is that the receiving rectangle is influenced not only by the main wave which we may think of as coming in a straight line from the sending station, but by the numerous other waves coming by longer paths and converging on the receiving rectangle by virtue of their having suffered either partial reflection at various surfaces of different electrical constants or having passed through regions of such electrical constants as to produce what may be described, roughly, as prism or lens action.

It is evident that these reflected and refracted portions will arrive at the receiving rectangle from various directions and in various phases. They may be resolved into two component parts-those which have an electric vector in the plane of the receiving rectangle and those which have an electric vector at right angles to that plane. The latter will produce no effect, but the former may be still further subdivided into two electrical components-one in phase with the electric vector of the main wave and the other $90^{\circ}$ out of phase with it. The latter is completely balanced out by the method of compensation employed. 
Its effect is to produce a very broad minimum and in some cases was so great that it could not be fully compensated out with the degree of coupling available at the point $M$ shown in Fig. I. It will be noted from the observations taken after dark that such very broad minima were quite frequently encountered. The other component of the electric vector in plane with the coil and in phase with the main wave may be compensated by slightly rotating the coil so as to oppose their action on that of the main wave. These components are the ones that produce the shift in the apparent bearing. The fact that this shift is less noticeable on a near-by station like Annapolis than it is on a more distant station like New Brunswick is due to the main wave of a near-by station being so much stronger than these reflected and refracted components and also to the fact that over a short distance there are less opportunities for such reflection and refraction to occur.

It may be confidently expected that with greater distances more marked deviation of the apparent bearing will appear. At the same time an average of a large number of observations will probably give settings which will check up well enough with the true bearing. From what is already known of the erratic behavior of transmission in a fog, it is not surprising that abnormal variations were obtained on the two foggy days of January 22 and 23. Neither is it surprising that greater variations are experienced in the sunset period and after dark than are found on a clear day, since it is well known that all signals vary enormously in intensity during these periods. The following sunset series was obtained on February 8 on New Brunswick. It will be noted that at 5.30 p. m. it was impossible to tell from what direction New Brunswick's signals were coming and that between 5.22 and $5.3^{8} \mathrm{p} . \mathrm{m}$. a variation of $68^{\circ}$ occurred.

NEW BRUNSWICK

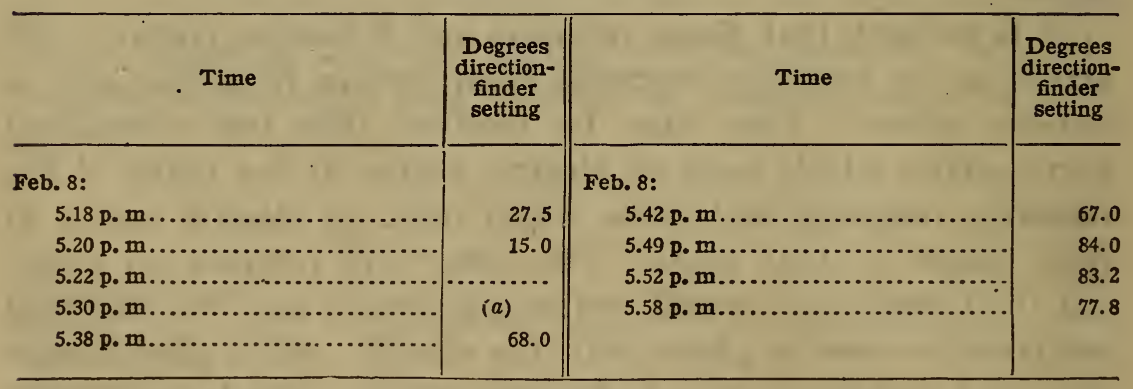

$a$ No minimum. 
Observations taken during the same period on Annapolis showed the fluctuations indicated in the following table:

ANNAPOLIS

\begin{tabular}{|c|c|c|c|}
\hline Time & $\begin{array}{l}\text { Degrees } \\
\text { direction- } \\
\text { finder } \\
\text { setting }\end{array}$ & Time & $\begin{array}{l}\text { Degrees } \\
\text { direction- } \\
\text { finder } \\
\text { setting }\end{array}$ \\
\hline Feb. 8: & & Feb. 8: & \\
\hline $4.08 \mathrm{p} . \mathrm{m} . . . \ldots \ldots$ & 19.9 & 5.35 p. m................................. & 23.8 \\
\hline 4.10 p. m.... & 19.5 & 5.37 p. m......... & 23.8 \\
\hline 4.18 p. m.......... & 21.5 & 5.44 p. m........................... & 21.0 \\
\hline $5.06 \mathrm{p} . \mathrm{m} \ldots \ldots \ldots \ldots$ & 25.3 & 5.45 p.m................................. & 21.0 \\
\hline 5.14 p. m.............. & 25.0 & 5.55 p. m............................... & 19.0 \\
\hline 5.24 p.m............ & 18.0 & 5.56 p. m.............................. & 18.8 \\
\hline
\end{tabular}

A large number of observations have been taken on wave lengths of 4000, 9200, 9800, 10 000, I3 600, and I6 $700 \mathrm{~m}$. It was soon discovered that very large variations in bearing

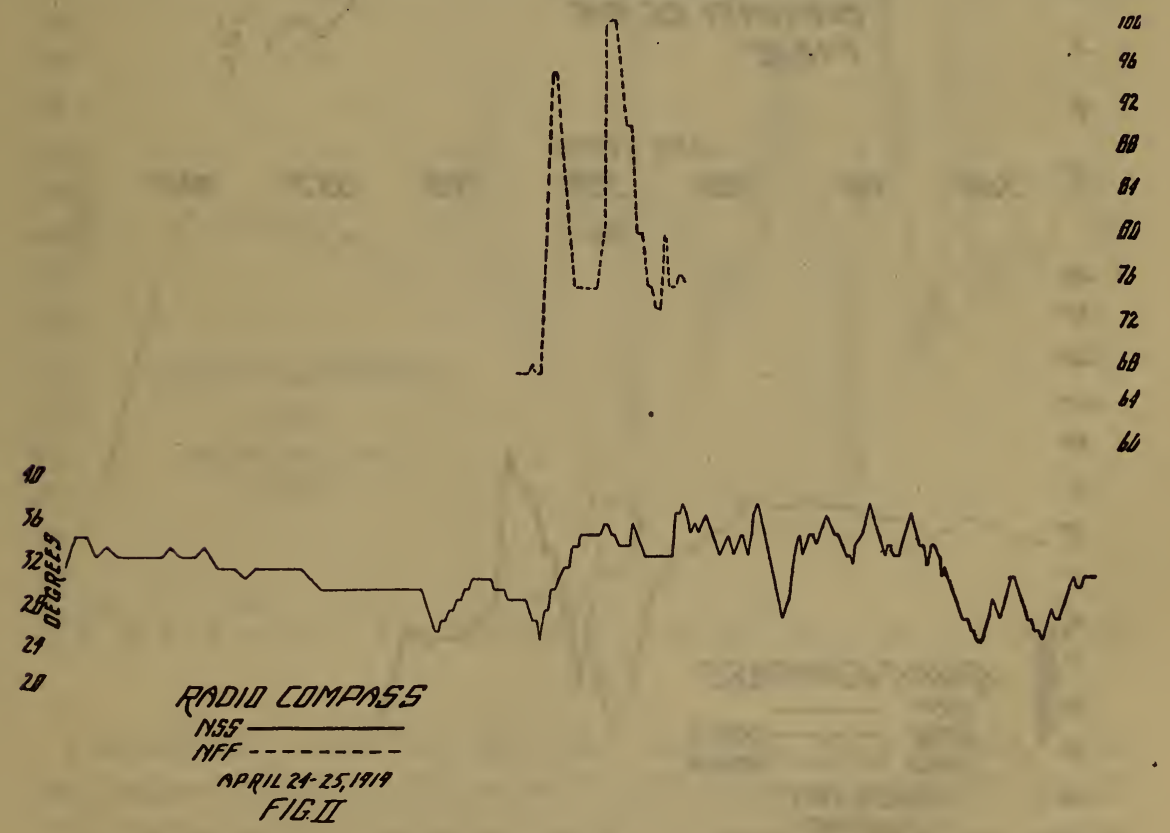

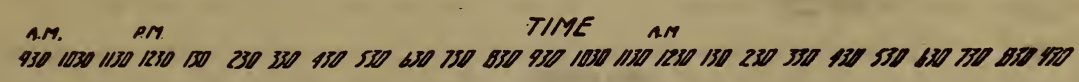

FIG. 2

occurred at night and that the variations, in general, were much worse on the long waves, the one exception to this being Annapolis on $16700 \mathrm{~m}$. This station is only 35 miles distant, which probably accounts for the small variations. Fig. 2 shows a typical variation 
on Annapolis over 24-hour period. For purposes of comparison, some observations on New Brunswick on i $3600 \mathrm{~m}$ are shown on the same sheet. Unfortunately New Brunswick did not transmit

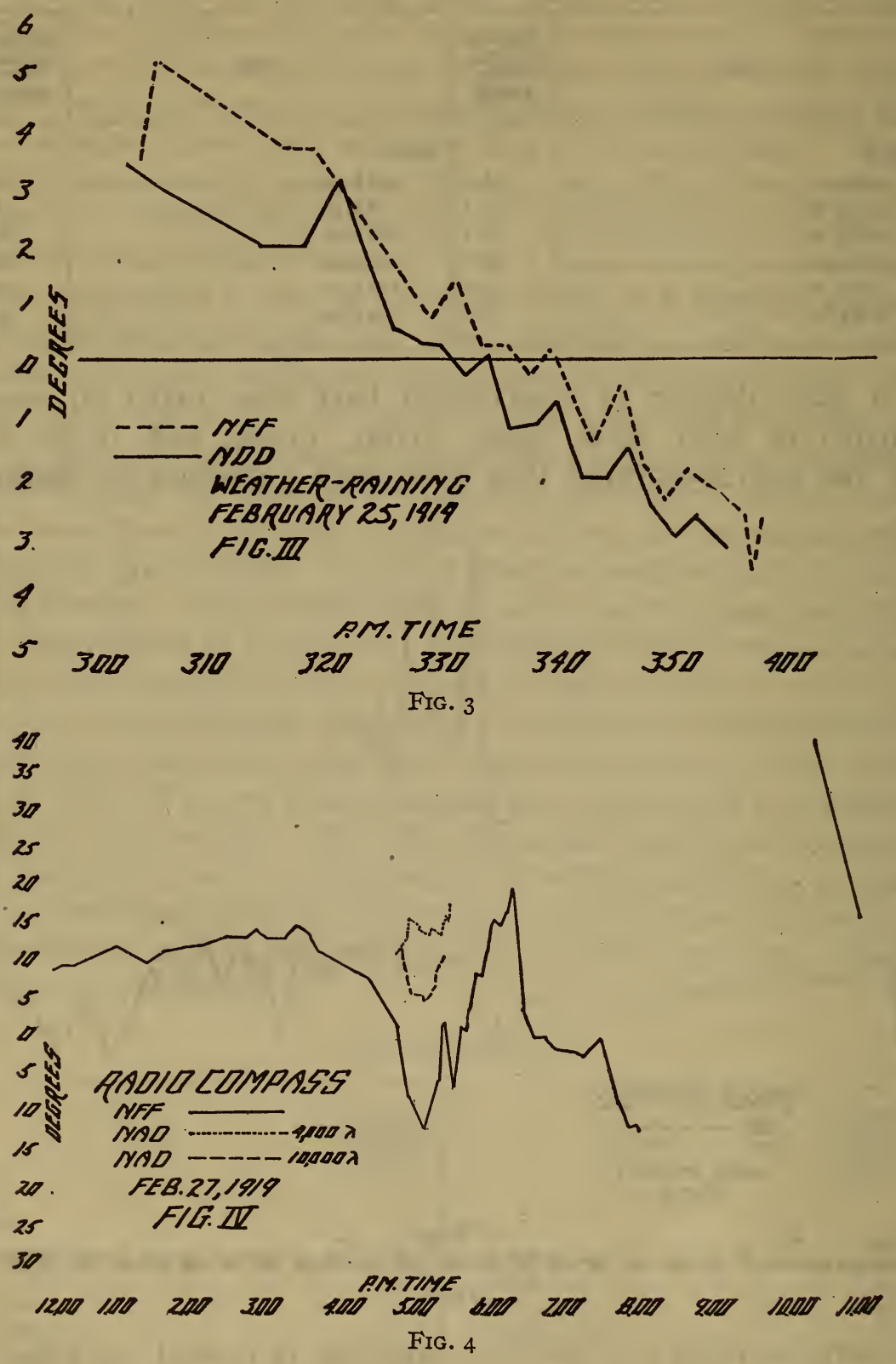

throughout the whole of this period. Fig. 3 shows the comparative variation during the afternoon of February 25, 1919, on New Brunswick on $13600 \mathrm{~m}$ and Sayville on $9800 \mathrm{~m}$. Fig. 4 
shows comparative variations on New Brunswick on $13600 \mathrm{~m}$. and Boston during the sunset period on 10000 and $4000 \mathrm{~m}$. The shorter wave seemed to give the least variation. Fig. 5 shows a typical 24-hour series on New Brunswick. It will be noted that between 3 and $4 \mathrm{a}$. $\mathrm{m}$. the bearing suffered a rotation of nearly $90^{\circ}$. A number of other observations have been taken on $4000 \mathrm{~m}$, some of them showing very bad variations, but in general less than those obtained on longer waves. Work on continuous waves shorter than $4000 \mathrm{~m}$ is under way.

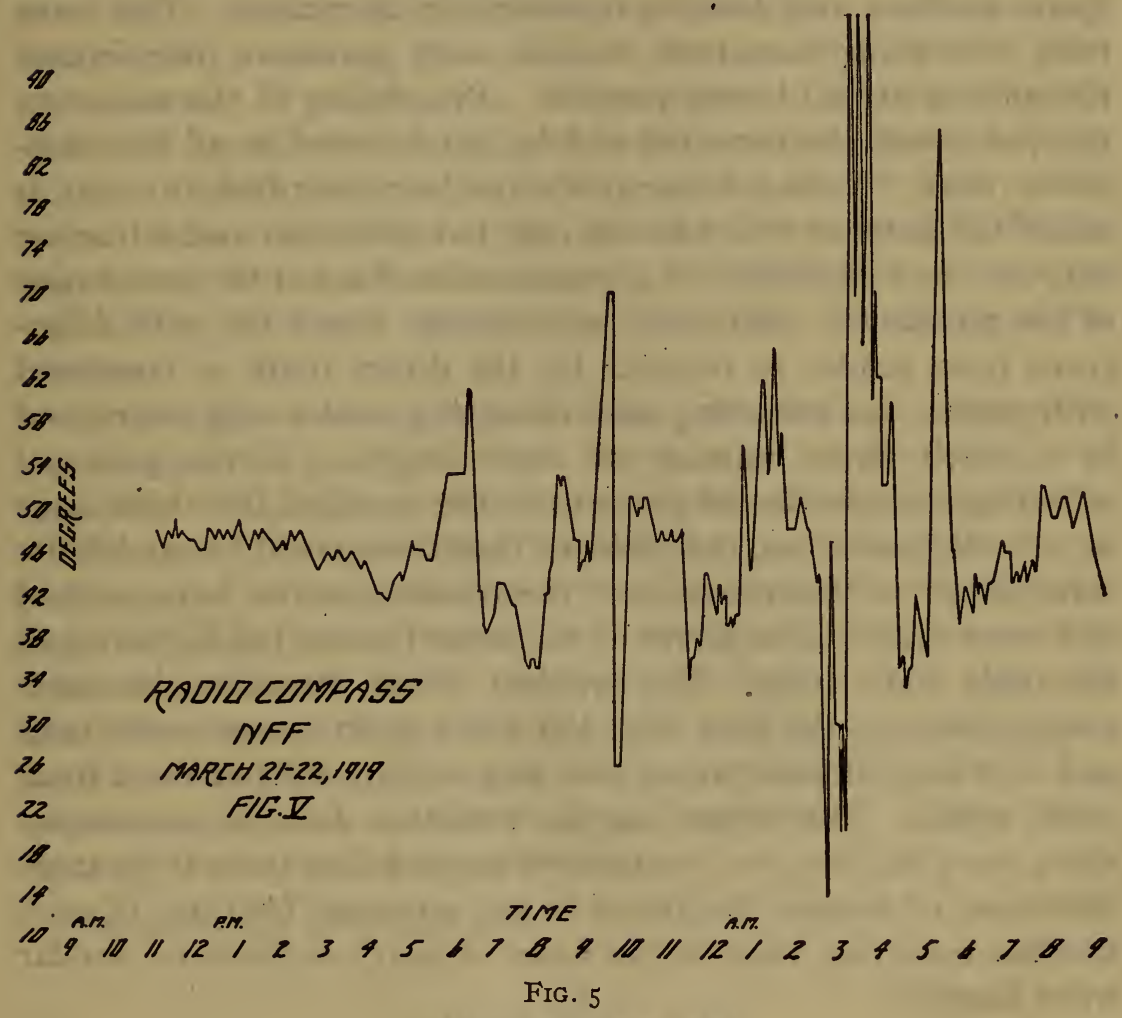

Considerable work has also been done on spark signals, with particular attention to the wave lengths of 952, 1200, and I $512 \mathrm{~m}$.

So far no serious variations have been observed on these waves, with the exception of a few series on Brooklyn and New York. Some of the Brooklyn observations at $\mathrm{I}_{5} \mathrm{I} 2 \mathrm{~m}$ taken on his press schedule between 9 and $9.40 \mathrm{p}$. $\mathrm{m}$. have shown a shift as large as $30^{\circ}$. The variation of the observations on New York at $9.52 \mathrm{~m}$ is partly accounted for by the fact that several stations are operated under the same call letter. On the other hand, their angular 
separation is only $12^{\circ}$, whereas the variations in bearing so far observed are more than double that amount.

Variations on short-spark waves are evidently quite rare and not nearly of as great magnitude as on the longer continuous waves. Results obtained at short-wave direction finder stations do not indicate variations of the order of magnitude herein described. This also is entirely understandable on the basis of the reflection and refraction idea. Short waves commonly used for direction-finding work between ship and shore are emitted by spark stations and have a considerable decrement. The wave train not being sustained, definite and persistent interference phenomena are no longer possible. Broadening of the minimum may, of course, be expected and in fact is noted in all directionfinder work. It has hitherto always been ascribed to what is called the antenna effect in the coil, but reflection and refraction may also be responsible for a considerable share of the broadening of the minimum. Moreover, with shorter waves the path differences from sender to receiver by the direct route as compared with routes via reflecting and refracting media will correspond to a much larger number of wave lengths. If the principal reflecting surfaces should prove to be the so-called Heaviside layer at very high altitides, it is evident that there could be no definite arrangement of interference at the receiver as the latter end of one wave train might arrive at the same time as the beginning of the main wave train. The problem would, therefore, be much complicated by the fact that the wave train is not continuous and it is very difficult to see how any definite shift of wave front could result. The writer has no available data on continuous short wave stations, but ventures to suggest that there is far more likelihood of serious deviations in the apparent bearings of such stations occurring than in the cases of spark stations on similar wave lengths.

\section{CONCLUSIONS}

A method of compensating the minimum and increasing the accuracy of direction-finder settings has been worked out for long waves. It has been shown that deviations of the order of $90^{\circ}$ may occur in the line of propagation of the resultant wave front in the case of very long continuous waves. The facts are fully in accord with the theory of propagation of such waves and the often expressed belief in the existence of media in the various layers of the earth's atmosphere which are capable of reflecting and refracting these waves. 
The value of long continuous waves for direction-finder work is, in view of these results, very doubtful. It is, of course, possible that observations taken over a more uniform surface like the sea would not show such marked variations. Observations on long continuous waves would be of value only if the observations cover a considerable period of time and show no very wide fluctuations.

It has been indicated that these results do not cast doubt upon the accuracy of direction-finder observations carried out on short wave spark stations, since consecutive interference according to a definite plan would not be as likely to occur when a damped wave train is used. The few cases of variations of bearing on spark signals so far observed seem to be accompanied by marked fading effects; as would be expected if they are an interference phenomena. Also the minimum was broadened very considerably in many cases, but in a few cases a rery bad fluctuation in bearing was accompanied by a sharpening rather than a broadening of the minimum.

No attempt in any of this work has been made to compensate local deflections so as to get the true bearing, as the writer was interested solely in time variations and not with local distortions.

It must be concluded that it would be very dangerous to use long continuous waves for direction-finder work at sea until it has been definitely proven that these variations do not occur when transmission is not partly or wholly overland. It is also very likely that even with spark stations it would not be wise to use longer waves than $500 \mathrm{~m}$ until it has been definitely shown that such waves do not vary in overseas transmission as they occasionally do in overland transmission.

WASHINGTON, July I5, I9I9. 